\title{
Article
}

\section{'It's about changing services and building relationships': evaluating the development of Children in Care Councils}

Thomas, Nigel and Percy-Smith, Barry

Available at http://clok.uclan.ac.uk/2875/

Thomas, Nigel ORCID: 0000-0002-5310-9144 and Percy-Smith, Barry (2012) 'It's about changing services and building relationships': evaluating the development of Children in Care Councils. Child \& Family Social Work, 17 (4). pp. 487-496. ISSN 1356-7500

It is advisable to refer to the publisher's version if you intend to cite from the work. http://dx.doi.org/10.1111/j.1365-2206.2011.00806.x

For more information about UCLan's research in this area go to http://www.uclan.ac.uk/researchgroups/ and search for <name of research Group>.

For information about Research generally at UCLan please go to http://www.uclan.ac.uk/research/

All outputs in CLoK are protected by Intellectual Property Rights law, including Copyright law. Copyright, IPR and Moral Rights for the works on this site are retained by the individual authors and/or other copyright owners. Terms and conditions for use of this material are defined in the policies page.

\section{CLoK}

Central Lancashire online Knowledge www.clok.uclan.ac.uk

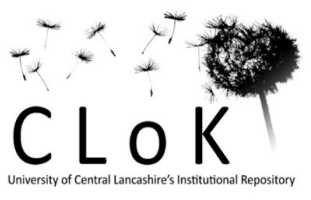




\title{
'It's about changing services and building relationships': Evaluating the development of Children in Care Councils
}

\author{
Nigel Thomas (University of Central Lancashire) \\ Barry Percy-Smith (University of the West of England)
}

\begin{abstract}
The introduction of Children in Care Councils under the Care Matters reforms in England set a challenge for local authorities to find effective ways by which children in care could contribute their views to the planning and provision of services. This paper discusses a review of progress across London which combined a survey of boroughs with focus group discussions with young people, local authority staff and elected members. The research found that considerable progress had been made in that virtually all boroughs had some mechanism for representing children in care, and that staff and young people were proud of their achievements. However, major challenges remain - to embed a culture of participation in services, to ensure succession, to reach all children including the many placed 'out of borough', and to defend what has been achieved in the face of severe cuts in public spending. The paper highlights a tension between empowering young people and meeting targets as corporate parents. The results support other research pointing to the need for a better understanding of the relationship between participation in governance and participation grounded in ordinary life.
\end{abstract}

Keywords: child care, children's participation, children's rights, looked after children, policy/management 


\section{Introduction}

The UK Government's White Paper Care Matters: Time for Change (Department for Education and Skills 2007) proposed that every local authority in England should establish a Children in Care Council 'to ensure that every child has the opportunity to air their views' and so that "children and young people should be able to put their experiences of the care system directly to those responsible for corporate parenting' (p. 21). Although there was no statutory requirement, in November 2009 the Department for Children, Schools and Families (2009) reported that more than $75 \%$ of authorities either had or were planning to set up a Children in Care Council, and the Secretary of State subsequently wrote to all authorities requesting that those which had not already done so should establish a Council during 2010. The research reported in this paper was commissioned by London Councils in order to understand the apparent variation in practice across the capital and the experiences of local authorities in establishing Children in Care Councils, with a view to 'developing effective participation mechanisms for children in and leaving care'.

The development of Children in Care Councils follows on, and seeks to formalise, earlier attempts to 'give a voice' to children and young people in care. In this article we review this development in the context both of those preceding attempts and of wider discussions of children and young people's participation, focusing on the evidence from our study in one city.

\section{Background}

A key aim of Care Matters was to 'give a stronger voice to children and young people in care, particularly by the development of Children in Care Councils' (Department for Children, Schools and Families 2009, p. 6). The White Paper stated:

It is important that children have a chance to shape and influence the parenting that they receive at every level - from expressing their wishes and feelings about the individual care they receive in their placements, through to helping to shape the overall strategy for children in their area through a Children in Care Council.

(Department for Education and Skills 2007, p. 20) 
The expectation that children should be able to express their wishes and feelings about the individual care they receive is relatively long-standing. The Children Act 1975 required a local authority, in reaching any decision relating to a child in their care, to ascertain and give due consideration to the wishes and feelings of the child, having regard to his (or her) age and understanding. The Children Act 1989 extended this to a requirement that encompassed decision-making before a child was looked after, and added a duty to consider complaints and representations from looked after children and children in need. ${ }^{1}$ It also required courts to have regard to the wishes and feelings of the child when making any decision regarding upbringing. The broader emphasis on children's wishes and feelings in the Children Act 1989, reinforced by extensive guidance and training, and coinciding with the adoption of the United Nations Convention on the Rights of the Child (CRC), meant that greater attention began to be paid to this issue in policy and practice.

The expectation that children should also help 'to shape the overall strategy for children in their area' is a more recent development, although it is something for which young people's advocacy organisations have been pressing for many years and which a number of local authorities and voluntary agencies have tried to implement (see Kirby et al., 2003). It received statutory support in the Children and Young People's Plan (England) Regulations 2005, which require local authorities to consult children, 'relevant young persons' and bodies representing them in the process of preparing children and young people's plans. ${ }^{2}$

The CRC commits the UK to uphold children's right to express their views freely 'in all matters affecting the child, the views of the child being given due weight in accordance with the age and maturity of the child' (Article 12); and also to freedom of expression, including 'freedom to seek, receive and impart information and ideas of all kinds' (Article 13) and freedom of association and peaceful assembly (Article 15). All these provisions are relevant to the participation of children in care. The Committee on the Rights of the Child (2009) is clear that Article 12 applies 'not only to the child as an individual, but to groups of children and children in general', and specifically mentions children in alternative care: 'mechanisms must be introduced to ensure that [such children] are able to express their views and that

\footnotetext{
${ }^{1}$ The Adoption and Children Act 2002 added a duty to provide advocacy services to those making representations.

2 In this instance 'children' are those under 18, and 'relevant young persons' are those (normally up to 21) still entitled to services after leaving care.
} 
those views be given due weight' in matters concerning them. Such mechanisms may include, 'for example, a representative council of the children... with the mandate to participate in the development and implementation of the policy and any rules of the institution' (2009: 22). For 'institution' here it is reasonable to read a commitment to wider involvement in the policies and procedures of agencies providing care.

Broadly speaking, this is the legal and policy context for initiatives to promote forms of collective participation by children and young people in care. Such initiatives form part of a wider movement to develop children and young people's voice and participation in public life, which has grown in strength and prominence globally in recent decades, especially since the adoption of the CRC. In the UK this has been characterised by an evident commitment from Government (in England, Wales, Scotland and Northern Ireland) to promote a variety of approaches to consultation with children and young people in public services and public policy (Kirby et al., 2003), and support for representative organisations such as youth councils and school councils - which are now present in around 90\% of schools in England (Whitty and Wisby 2007).

Consultation is not participation, and some of this activity has been criticised as tokenistic (Badham 2004; Matthews 2003; Tisdall and Davis 2004) or oppressive (Cooke and Kothari 2001). Sinclair (2004) notes that in practice participation is often used to mean being listened to or consulted, in contrast with 'active' participation where children 'have reason to believe that their involvement will make a difference' (110-1). There is evidence that results are more impressive in the personal rewards that children and young people gain from taking part, in skill development and social contact, than in any perceptible impact on policy and services (Percy-Smith 2007).

Attempts have been made to construct typologies of participation, to reflect variations in practice and purpose. The 'ladder of participation' (Hart 1992) aims to distinguish tokenistic versions of 'participation' from those which genuinely involve children and young people in shared decision-making or in initiating change. Shier (2001) offers a model built on five levels of participation:

1. Children are listened to;

2. Children are supported in expressing their views;

3. Children's views are taken into account; 
4. Children are involved in decision-making processes;

5. Children share power and responsibility for decision-making.

At each level, organisations may have differing degrees of commitment to the process of empowerment. Shier suggests the minimum level compatible with Article 12 is where the organisation is ready to take children's views into account and has processes and policies that enable and require this (level 3); but that real participation means including children directly in the decision-making process (4 and 5).

A recent review of participation in England concluded that there has been significant change in the way that local and national government and other organisations work with children, 'empowering children to have a say in decisions that affect their lives', with 'a steady rise in the number of structural mechanisms to enable children to participate in decision-making' and 'a cultural change in the value children, adults and organisations are now placing on children's views' (Davey 2010: 7).

There is little research about collective participation by children in care, but children's participation in individual decision-making in care has a longer history and has been more extensively researched (Thomas 2000, Munro 2001, Cashmore 2002). Consistent findings, which may be relevant here, are that children are easily marginalised when decisions are perceived as more important or difficult, that for children to take part effectively decisionmaking structures and processes must be adapted to their preferred communication style, and that support, advocacy and information are of crucial importance.

There is a tendency for participation structures to 'mimic' adult arrangements, for example youth parliaments, councils and forums (Thomas 2007). In evaluating participation in Children's Trusts, Percy-Smith (2009) found that such structures, whilst beneficial for young people, seldom had much influence on decision-making. He developed a typology which distinguished between direct involvement (in decision-making, funding decisions, youth-led service provision, campaigns and lobbying) and indirect involvement (in consultations and surveys, inspections and reviews, information and awareness of services). Within this schema 'forums' and 'councils', such as those studied here, may be seen as examples of 'indirect involvement' since, although young people are involved in discussions about policies and services, they do not have direct input into final decision-making. However, there are other elements which lend themselves to a more 'hybrid' interpretation; several Councils were 
involved in direct provision of support and advice to young people, or campaigning and lobbying.

In this research we wanted to see how far local authorities had been able to develop processes and structures that enabled children to exercise their minimum rights under the $\mathrm{CRC}$, and also looked for examples that went beyond this to achieve elements of shared decision-making. Our primary questions, however, were how far they had succeeded in complying with Government expectations, what had been the challenges in achieving that, and how effective were the opportunities for children in care to be involved.

\section{Methods}

The objectives set by the funders were:

- To develop a comprehensive map of existing provision of Children in Care Councils across London.

- To gain a clear understanding of the experiences and challenges faced by London local authorities in establishing and delivering effective Children in Care Councils.

- To identify and share examples of best practice in the development and delivery of Children in Care Councils.

The research adopted an approach that explored the experiences of developing Children in Care Councils from different perspectives, and in addition provided opportunities for stakeholders to engage in a process of reflective inquiry in response to emerging findings as part of the evaluation, in order to inform the future development of participation.

A review of the policy and research literature and relevant practice guidance enabled the research team to understand the wider context in which Children in Care Councils were being developed, and also generated questions to explore further in the research (see below). A questionnaire survey of participation workers (staff members identified in each authority as responsible for supporting the participation of children in care), followed by telephone interviews with participation workers and in some cases with service managers, enabled information to be gathered on which boroughs had set up Children in Care Councils, their 
history and mode of operation. Two thirds of London boroughs (22 out of 32) responded to the initial survey, and a total of 24 staff in those boroughs were subsequently interviewed. Following this, focus groups were planned and undertaken with young people, participation workers, managers and elected members. These were conducted as action inquiry groups, and explored participants' experiences and understandings in terms of successes and challenges. Ten young people, four participation workers, four managers and three elected members, from a total of 12 boroughs, took part in these discussions. Young people were recruited through an open invitation to all children in care councils sent via the participation worker.

Four site visits were also undertaken to children's homes and other venues, in order to understand particular examples of practice and to meet with particular groups of young people. Finally, an evaluation workshop was held with focus group members and other research participants, in order to share emerging findings from the research, undertake further inquiry into key issues, reflect on the future participation of children in care, and contribute to the final recommendations. Participants in this workshop included three elected members, two service managers, six participation workers and eight young people, from 12 local authorities.

The research took place between May and September 2010. The results are discussed in terms of: the development of Children in Care Councils; governance, relationships and roles; the impact of Children in Care Councils; and challenges to future development.

\section{Development of Children in Care Councils}

Of the 22 boroughs which provided full information, all had a Children in Care Council or were planning to create one. Frequently a different name was used, 'Children in Care Council' being seen as off-putting or labelling, but we use it here, shortened to 'CiCC', for ease of reference. One borough did not have a CiCC, but was planning to establish one in the coming year. No assumptions can be made about participation in the boroughs that did not respond at this stage; at least one took part in a later phase of the research, and did appear to have a CiCC. 
The purpose of CiCCs was generally seen to involve representing the voices of children in care and care leavers through a variety of consultative mechanisms, influencing those who make decisions about services, and monitoring the delivery of the 'Pledge' and other policies. The Pledge, introduced in Care Matters, is developed in each local authority, with input from children, to ensure that children in care are aware of their rights and opportunities (Department for Education and Skills 2007, p. 22). The boroughs had worked together to produce a London Pledge (Young London Matters 2008), complementing the local Pledge in each borough. Young people saw the CiCC as an opportunity to 'have their own voice' and take a lead. They emphasised the importance of achieving tangible improvements in services, not only for themselves but for younger children:

I don't want them to go through what I've been through.

Care leaver

The methods used to set up a $\mathrm{CiCC}$ varied considerably, reflecting the progress already made in the borough to engage with children in care and care leavers, as well as the degree of commitment to the idea of a CiCC. Some boroughs built on an existing group, others consulted children in care more widely about what they wanted from a CiCC, while a few contracted an outside organisation to operate a CiCC for them.

CiCCs varied in size from below five to more than 20 members. This partly reflected the length of time for which groups had been running. The larger CiCCs often grew from an established group of young people, some of which had been active for more than five years. Newer CiCCs had to work harder to promote themselves and engage young people.

The majority of CiCCs were open to all children in care and care leavers. A minority set a maximum number of members. Some set lower age limits, commonly around 10 years, and a few set upper limits $(18,21$, or 24). Broadly speaking, membership tended towards the upper end of the age range, including many care leavers. Anecdotal evidence suggested girls were more involved than boys, as were young people in stable foster placements and those already known to participation workers. CiCCs with broader membership often had systems in place to ensure a flow of new recruits, such as 'feeder groups', and were more likely to have specific arrangements for groups such as younger children, disabled children or unaccompanied asylum seekers. 
It was possible to identify several models of CiCC:

1. An established group, with an active membership and role in decision-making, often developed from a pre-existing group.

2. An independent group away from the local authority, often 'outsourced' to another agency, again with an active role in decision-making.

3. An informal 'youth club' with an element of consultation work, without fixed membership.

4. A 'political arm' of a network of groups (e.g. support or advocacy groups, youth clubs or drop-ins), representing their combined interests.

5. A 'research team' focused on consulting other young people and presenting issues to corporate parenting bodies.

Although a majority of authorities had set up a CiCC, the fact that most had fewer than 20 young people raises questions about their effectiveness, given the general lack of mechanisms to ensure democratic representation and communication with other children in care. Members tended to be seen as 'the voice of children in care' simply because they had been in care themselves. Some groups did make concerted efforts to engage with other children in care, as the following comment illustrates:

We're doing a fun day soon, a lot of us older ones chatting with them playing with them, finding things out, then coming back and writing things up and voicing what they've said.

\section{CiCC member}

The majority of CiCCs met once or twice a month, others less often. Some used 'youthfriendly' venues such as youth centres, others official venues like town halls. There was concern that in official settings conventional models of decision-making tend to be reproduced, and acknowledgement of a need to engage with young people in everyday community contexts. It was common for meetings to be led by young people and run in a relatively informal way. Young people might elect their own Chair, set the agenda and take minutes, although in some boroughs discussions were led by the participation worker. This appeared to relate to the ability and confidence of the young people and the stage of development of the CiCC.

The most common activities of CiCCs were seen to fall into four types: 


\section{a) Direct involvement in local authority services}

Many CiCCs were involved in staff recruitment, induction and training, and some in inspections of services. These were opportunities for young people to influence directly how services are provided, and were experienced by them as meaningful participation.

\section{b) Consultation activities}

Consulting other children, and participating in national consultations, were common activities. Responding to consultations is one way in which young people can participate in decisions about services. At the same time young people were clear that there was a need for more direct involvement in decision-making, through dialogue and regular meetings with the corporate parenting board and elected members.

\section{c) Publicity, promotion, information and campaigning}

CiCC members saw helping to write the local Pledge, and producing information about how young people can participate (newsletters, magazines, websites and videos), as important ways to become involved. Some had organised events for children in care and campaigned around specific issues such as meeting Pledge commitments.

\section{d) Developing personal skills}

Participation tends to be seen in terms of young people having a say in decisions. However, this research also showed the importance of activities that supported personal development of members, for example work experience, gaining qualifications, volunteering and social activities which provided opportunities for developing identity and building social capital.

Most boroughs rewarded participants in their CiCCs, often using vouchers or an hourly payment. Office holders such as Chairs might have sessional contracts, and members be paid for providing training.

\section{Governance, relationships and roles}

Participation is in large part about influence on decision-making, and therefore about governance. The research looked for evidence of systemic relationships between the CiCC 
and the leadership of children's services in the local authority, where key responsibility for corporate parenting resides. Of the 22 responses, 17 reported that the $\mathrm{CiCC}$ met both with the director of children's services and with elected members (although it was not always clear how often) and 18 met the corporate parenting panel or board, in many cases at quarterly intervals. However, although there was frequent dialogue with decision-makers, this did not appear to involve direct involvement in decision-making processes, as we see in the following section.

Since governance is partly dependent on the quality of relationships and interactions, it is instructive to consider the roles of different personnel in the operation of CiCCs. We look in turn at participation workers, social workers, managers and elected members.

The primary role of participation workers was seen as to facilitate the operation of CiCCs and wider participation of children in care and care leavers. This included finding venues, navigating local authority systems, being a researcher for the $\mathrm{CiCC}$ and an advocate for the group. Participation workers wanted young people to be at the centre of decision-making about services, and saw it as their role to support that. As one put it, the role can't be just a job, it has to be a passion. It takes a lot of different skills, reflective people who are tenacious, very involved - and fundraisers.

Participation worker

There was some tension between facilitating and supporting young people to speak directly to decision-makers and actually speaking on their behalf. How this was resolved reflected a combination of factors: the stage of development of the CiCC and members' skills and confidence; how well participation was embedded with political and professional leadership in the borough; and the skill and understanding of the participation worker.

Social workers were frequently seen as less supportive of young people's participation. It was suggested that many had limited understanding of the purpose or value of the $\mathrm{CiCC}$, and were reluctant to make referrals. Young people attributed this to frequent changes of worker, use of agency staff, unmanageable workloads and, in some cases, to a lack of interest in young people. It should be emphasised that social workers did not participate directly in this research. 
And he's there holding this social worker's hand and then the social worker leaves, and then we get another social worker, and just as we start to trust him, 'Bye'.

Young person

Concerns were also expressed in relation to the commitment of social work managers. One CiCC member noted: 'We have a better relationship with Directors than with team managers.' Where good relationships had been established with heads of service, there was evidence that participation had more impact. There were some tensions around the potential for young people to say something 'difficult'; service managers were sometimes thought to be wary of putting young people in front of Directors or elected members because 'young people don't always say things diplomatically' (Participation worker). Young people questioned how well some professionals were able to engage with them, provide appropriate settings and opportunities for them to participate, and treat them with respect and understanding.

As for relationships with elected members, the fact that 17 CiCCs met with councillors was encouraging. However, there was a feeling that public decision-making structures were not conducive to participation of young people. In one case it was suggested that the political cycle did not support continuity and consistency, with frequent changes of lead member. However, in the same authority a councillor from each political group attended every meeting of the CiCC, with young people leading the meetings. Some young people were very positive about their experience of contact with political leaders:

We secured funding from the mayor. Originally he said no but we turned around and went to him and said we're your corporate kids, would you deprive your child from using your living room? So why are you depriving us? So we sort of put it to him like that and he couldn't say no after that.

Young person

Elected members showed high levels of commitment to the participation of young people, but admitted needing more support and learning to make participation effective. Similarly, it was apparent with heads of service and managers that the need for support in embedding participation within their systems constituted a major barrier to involving children in care in design, development and review of services. 


\section{Impact of Children in Care Councils}

At a time when public sector spending is under extreme pressure, questions about impact and effectiveness are salient. Attempts to assess impact of participation have distinguished between personal impact, impact on relationships and impact on services (Kirby 2002; Kirby et al. 2004; Crowley and Skeels 2010); in what follows we consider all these aspects.

Focus group participants were invited to reflect on how the CiCC was actively engaged in decision-making, using a 'decision-making cycle' with the following stages:

1. Identifying issues

2. Inquiry and discussion

3. Decision making

4. Action

5. Evaluation and review

Although patterns varied from issue to issue, participants usually identified some combination of stages 1, 2, 4 and 5 as points where the CiCC or its members would be engaged. No adult participant identified stage 3, but several young people did, giving the example of recruitment panels. This suggests that issues where young people were able to participate most fully were not around strategic or operational management, but in 'niche' areas such as recruitment, induction and training. Young people saw this as an example of active participation in something that directly affected them; for example, a 'buddying' scheme in one borough which partnered newly qualified social workers with children in care over their first year of service.

Elsewhere young people's participation was expressed in campaigns around particular issues such as a failure to implement the Pledge, housing policy for care leavers, or 'bin bag moves.' However, these remain isolated examples, rather than systematic evidence of profound impact. Given the newness of some CiCCs, it is understandable that their role is underdeveloped. However, even where CiCCs have been established for longer, it was often unclear what systematic influence the group had, beyond recruitment and training of frontline staff. 
For local authorities there may be a tension between empowering young people and meeting performance targets for corporate parenting; although, as one borough informed us, those targets may not reflect what young people need. A more responsive approach to service provision can be achieved through participation perceived as dialogue and joint inquiry (see Percy-Smith and Weil 2003; Fielding 2006).

Whilst being committed to make things better for all children in care, young people also emphasised the personal benefits they got from taking part: developing confidence and selfesteem, pride, independence and self-advocacy. Psycho-social benefits included a sense of identity and agency derived from meeting other young people in care, sharing experiences and providing peer support; practical benefits included direct support services and social goods such as driving lessons, money, information about their rights, and access to education and apprenticeship opportunities.

It's not just that it's our Council - we are all really good friends.

Young person

This demonstrates the importance of understanding participation more widely than just involvement in public sector decision-making. As others have argued, community participation and self-help can provide more meaningful and effective empowerment than devolving responsibility to local authorities (Dadich 2010; Sancar and Severcan 2010). This resonates with recent critiques of 'participation' which focus on self-determination (Williams et al 2010; Percy-Smith 2010a), and with earlier emancipatory discourses (Freire 1972).

However, it is notable that these benefits are only available to those who directly participate in the CiCC's work. Whilst CiCCs may have some potential as representative bodies, as forums for direct participation they are limited unless larger numbers of young people access them.

\section{Challenges for future development}

Participants were asked to point to the main challenges and barriers to the development of CiCCs. Four issues emerged: funding and resources; continuity and succession planning; engaging with hard to reach groups; and embedding participation in organisational culture. 
With public spending cuts looming, funding was raised as a matter of grave concern. The general view was that the funding required to support an effective CiCC was relatively small, but a basic level was essential to enable it to meet regularly, engage in activities, reward young people and promote its work. Employing participation workers was critically important. Young people and staff saw lack of funds as the main factor holding back their work. It is evident that the development of CiCCs will depend on the ability of local authorities to protect a minimum level of spending to enable them to function, and find efficient ways of using, perhaps sharing, resources.

Succession planning and continuity were an area of concern; in many boroughs there was no clear route for new participants to get involved, with a high level of dependence on the participation worker. Where the membership had been long-established and stable, there were concerns about an absence of new and younger members coming through to take a lead. The 'feeder group' model, which in some boroughs supported a smooth transition for younger children on to the CiCC, seemed to offer one way forward. However, this is more difficult for the many children placed out of borough. Concern about succession planning and continuity was connected to the issue of future funding: young people suggested that where CiCCs were still in early stages of development the lack of established infrastructure compounded financial uncertainty. The participation worker was seen as the lynchpin, keeping children and young people engaged and interested, organising meetings and events and advocating for the CiCC across the local authority. Yet investment in this resource was feared to be at risk as cuts begin to bite.

The challenge of engaging 'hard to reach' groups may refer to, for example, disabled children, younger children, refugee children, young mums, young offenders, young people involved in gangs, young people not in education, employment or training, or those who are unwilling to engage. Experiences of engaging with these groups are localised and contextual, with some local authorities finding it hard to engage a particular group such as asylum seekers while others found them easy to work with (in one CiCC this was the dominant group). This issue, then, demanded local solutions such as activities tailored to particular groups and targeted entry routes such as football or dance classes, as well as ensuring that staff were aware of the $\mathrm{CiCC}$ and actively encouraged young people to engage. Young people 
and participation workers were aware that those currently participating were often selfselecting, and made constant efforts to seek wider views.

The most 'hard to reach', however, were those placed 'out of borough', of whom there are a high proportion in every part of London. In some cases this means being placed in a neighbouring borough, which can present its own challenges: a visit to young people in a children's home in north London revealed that none of them had heard of their CiCC or knew the participation worker from their home authority, although when they heard of the successes of CiCCs they expressed an interest in being involved, either by attending meetings or via the internet. However, many children are placed outside London, often in Wales, Scotland or Northern England, and for them it is not practicable to attend meetings in London. Alternative methods of engagement such as internet communication have been suggested, but appeared to present difficulty because of professional anxieties about using the internet to communicate with children. In only one borough were staff allowed to use a private Facebook group for their CiCC. It is of concern that children and young people placed 'out of borough' are not benefiting from opportunities to influence decision-making or participate with others. More work is needed to explore what effective participation for all young people in care might mean.

Participants generally considered that embedding a culture of participation remains the fundamental task in the long term. As one worker put it, participation must be 'an ingredient in the cake', not merely the icing. At one level this is about challenging the culture of participation as consultation, and uncertainty about how best to integrate young people's views into local authority systems. However, through the systemic inquiry process that participants engaged in, there was a realisation that part of the challenge relates to developing an understanding of participation as 'learning for change', through dialogue and critically reflexive practice that enables systems to adapt and change in response to young people (Kirby et al 2003; Percy-Smith 2010a).

Embedding participation means that all practitioners adopt participatory practices, rather than leaving it to the participation worker. Social workers' attitudes were seen as a key element in this. With the legal obligation to take account of children's wishes and feelings, their commitment to a broader participatory approach is critical to making children's engagement a reality. Yet there was felt to be a tension between being a good corporate parent and 
empowering young people; and also 'between championing young people and ticking Ofsted boxes.'

A highly performance-focused local authority will be hierarchical, top-down and undemocratic and one that does not support what we are trying to achieve, but is driven by the inspection regime.

Social work manager

At the conclusion of the research young people and their participation workers were invited to reflect on their hopes for CiCCs in the future, in response to these challenges. They expressed an ambition to deepen and widen their influence across local authority services and decision-making processes by firming up procedures, increasing their impact on policy development and corporate parenting, having more face-to-face contact with decision makers and more creative involvement in strategic planning, and generally becoming more vocal and empowered. As one young person put it, the $\mathrm{CiCC}$ wanted to become 'statutory'.

In all our contact with young people involved in CiCCs it was evident that there was a great deal of pride in their achievements. This was reflected in their motivation and commitment, and their concern to ensure the work would continue. At the same time, there was anxiety about dependence on others to secure the future existence of the $\mathrm{CiCC}$.

I think it takes certain kinds of people - who better to do that than people in care because we have faced those challenges?

Young person

\section{Conclusion}

It is clear from this study that most local authorities, in London at least, have embraced the importance of CiCCs and have made arrangements for participation by children in care. However, development has been driven by the commitment of participation workers rather than cultural change across authorities, and there are significant limitations. Although children and young people are taking a lead in CiCCs and deriving considerable benefit, only relatively small numbers are involved. Those in custody or placed outside London are seldom included or given access. Those who are involved have little direct influence on decision- 
making, and a major challenge has been to 'embed' participation so that children have real impact on decisions. Whilst there is now widespread commitment to involving children in care planning and reviews, participation by children collectively in decision-making is less advanced. To some extent this reflects the dominant model of decision-making in local government, where power resides with chief officers and elected members, who in turn are subject to control by central government.

This study shows the significant benefits that participation in CiCCs can have for children and young people. The results are consistent with other work suggesting the need for models of participation that reflect different cultural understandings and purposes (Percy-Smith and Thomas 2010; Percy-Smith 2010a). At a basic level one can distinguish between participation that looks 'upward' to its impact on decision-making and service development, and participation with a more horizontal orientation toward personal benefits for young people taking part. A fundamental challenge is to bring these together in ways that can reflect both the agendas and priorities of service providers and young people's experiential realities, connecting lifeworlds and systems (Habermas 1987; Kemmis 2001; Percy-Smith 2010b). This means extending the focus beyond the current emphasis on participation for effective services (Fielding 2006) to how, through diverse forms of participation, young people can become empowered as citizens, having more of a role as social actors in the everyday contexts in which they live. It also means a commitment to explore what it might mean to transform an inherently non-participatory hierarchical system, in which even practitioners have little voice and influence, into a learning organisation which actively supports the democratic engagement of all stakeholders in learning for change.

This evaluation has highlighted the need for more research, particularly action research, to understand how to integrate participation effectively into local authority systems, and what are the barriers and enablers in bringing about the cultural change in local authorities that will make participation of children in care more effective. However, for embattled local authorities and those who work in them, a more immediate challenge is how to preserve the limited gains that have already been made in enabling children in care to have a voice in their services. 


\section{References}

Badham, B. (2004) 'Participation - for a change: disabled young people lead the way', Children \& Society 18(2), 143-154.

Cashmore, J. (2002) 'Promoting the participation of children and young people in care', Child Abuse \& Neglect 26(8), 837-47.

Committee on the Rights of the Child (2009) General Comment No. 12 (The right of the child to be heard), Geneva: Office of the United Nations High Commissioner for Human Rights.

Cooke, B. and Kothari, U. (eds) (2001) Participation: The New Tyranny? London: Zed Books.

Crowley, A. and Skeels, A. (2010) 'Getting the measure of children and young people's participation', in Percy-Smith B. and Thomas, N. (eds) A Handbook of Children and Young People's Participation: Perspectives from Theory and Practice, London: Routledge.

Dadich, A. (2010) 'Participation among young people with mental health issues: redefining the boundaries', in Percy-Smith B. and Thomas, N. (eds) A Handbook of Children and Young People's Participation: Perspectives from Theory and Practice, London: Routledge.

Davey, C. (2010) Children's Participation in Decision-Making: a summary report on progress made up to 2010, London: NCB for Participation Works.

Department for Children, Schools and Families (2009) Care Matters: Ministerial Stocktake Report 2009, Nottingham: DCSF Publications.

Department for Education and Skills (2007) Care Matters: Time for Change, London: The Stationery Office.

Fielding, M. (2006) 'Leadership, radical student engagement and the necessity of personcentred education', International Journal of Leadership in Education, 9(4), 299-313.

Freire, P. (1972) Pedagogy of the Oppressed, Harmondsworth: Penguin. 
Habermas, J. (1987) The Theory of Communicative Action. Vol. 2: Lifeworld and System: a critique of Functionalist Reason, Boston MA: Beacon Press.

Hart, R. (1992) Children's Participation: From Tokenism To Citizenship, Florence: UNICEF.

Kemmis, S. (2001) Exploring the Relevance of Critical Theory for Action Research: Emancipatory Action Research in the Footsteps of Jurgen Habermas, in Reason, P. and Bradbury, H. (eds) Handbook of Action Research: Participative Inquiry and Practice, London: Sage.

Kirby, P. with Bryson, S (2002) Measuring the Magic, London: Carnegie UK Trust.

Kirby, P., Lanyon, C., Cronin, K. and Sinclair, R. (2003) Building a Culture of Participation: Involving Children and Young People in Policy, Service Planning, Delivery and Evaluation (Research Report), London: Department for Education and Skills.

Kirby, P. Laws, S. and Pettitt, B (2004) Assessing the Impact of Children's Participation: A discussion paper towards a new study (Unpublished paper), London: Save the Children.

Matthews, H. (2003) 'Children and regeneration: setting an agenda for community participation and integration', Children \& Society 17(4), 264-276.

Munro, E. (2001) 'Empowering looked after children', Child \& Family Social Work 6(2), 129-37.

Percy-Smith, B. (2007) Evaluating the development of children's participation plans in two Children's Trusts, Interim Report Year 1. Leicester: National Youth Agency

Percy-Smith, B. (2009) Evaluating the development of young people's participation in two Children's Trusts, Year Two report. Leicester: National Youth Agency

Percy-Smith, B. (2010a) Councils, consultation and community: Rethinking the spaces for children and young people's participation, Children's Geographies 8(2), 107-122. 
Percy-Smith, B. (2010b) 'Connecting systems and young people's lifeworlds: From participation to empowerment?' Child Participation Workshop, Centre for the Study of Childhood and Youth, Sheffield University, $26^{\text {th }}$ January.

Percy-Smith, B. and Thomas, N. (eds) (2010) A Handbook of Children and Young People's Participation: Perspectives from Theory and Practice, London: Routledge.

Percy-Smith, B. and Weil, S. (2003) 'Practice-based research as development: innovation and empowerment in youth intervention initiatives using collaborative action inquiry' in Bennett, A. (ed.) Researching Youth, Basingstoke: Palgrave.

Sancar, F. and Severcan, Y. (2010) 'In search of agency: Participation in a youth organisation in Turkey' in Percy-Smith B. and Thomas, N. (eds) A Handbook of Children and Young People's Participation: Perspectives from Theory and Practice, London: Routledge.

Shier, H. (2001). 'Pathways to participation: openings, opportunities and obligations', Children \& Society 15(2): 107-117.

Sinclair, R. (2004) 'Participation in practice: making it meaningful, effective and sustainable', Children \& Society 18(2), 106-18.

Thomas, N. (2000) Children, Family and the State: Decision-making and Child Participation, Basingstoke: Macmillan (paperback edition 2002, Bristol: Policy Press).

Thomas, N. (2007) 'Towards a theory of children's participation', International Journal of Children's Rights 15(2), 199-218.

Tisdall, K. and Davis, J. (2004) 'Making a difference? bringing children's and young people's views into policy-making', Children \& Society 18(2), 131-142.

Whitty, G. and Wisby, E. (2007) Real Decision Making? School Councils in Action (Research Report DCSF-RR001), London: Department for Children, Schools and Families. 
Williams, C., Edlin, J. and Beals, F. (2010) 'Commentary 6: Spaces and structures: looking from the outside' in Percy-Smith B. and Thomas, N. (eds) A Handbook of Children and Young People's Participation: Perspectives from Theory and Practice, London: Routledge.

Young London Matters (2008) The London Pledge for Children and Young People in Care, http://www.londoncouncils.gov.uk/policylobbying/children/incare/lpcypic/default.htm (accessed 15/02/2011).

\section{Acknowledgements}

Acknowledgements are due: to the two anonymous reviewers; to Clive Grimshaw, Elizabeth Cheesbrough and Naomi Naughton, who worked with the authors on the evaluation; to Addicus Cort and colleagues at London Councils; above all, to the young people, professionals and elected members who gave their time and ideas to the study. 